\title{
Parathyroid Ablation in Dystrophic Hamsters
}

\author{
EFFECTS ON CA CONTENT AND HISTOLOGY OF HEART, \\ DIAPHRAGM, AND RECTUS FEMORIS
}

\begin{abstract}
Genaro M. A. Palmieri, David F. Nutting, Syamal K. Bhattacharya, Tulio E. Bertorini, and JAMEs C. Williams, Departments of Medicine, Physiology and Biophysics, and Neurology, University of Tennessee Center for the Health Sciences, Memphis, Tennessee 38163; St. Jude Children's Research Hospital, Memphis, Tennessee 38101; Department of Chemistry, Memphis State University, Memphis, Tennessee 38152
\end{abstract}

\begin{abstract}
A B STRACT Cumulative evidence indicates that there is an increased accumulation of calcium in dystrophic muscle and that this may have a pathophysiological role in the progression of the dystrophic process. The accumulation may be related to a defect of the plasma membrane. Because parathyroid hormone (PTH) stimulates calcium influx into the cytosol, the chronic effects of surgical ablation of the parathyroid glands on muscle $\mathrm{Ca}, \mathrm{Mg}$, protein synthesis, and histology, as well as plasma creatine phosphokinase (CPK), $\mathrm{Ca}$, and $\mathrm{Mg}$, were studied in normal and dystrophic (BIO 14.6) hamsters. Thyroparathyroidectomized (TPTX) hamsters receiving replacement doses of $\mathrm{L}$ thyroxine were killed at age $90 \mathrm{~d}, 55 \mathrm{~d}$ after TPTX. In intact dystrophic hamsters, the Ca content in the heart was 20 times higher than in normal animals and was reduced by half in TPTX dystrophic hamsters. Similar results were observed in diaphragm and rectus femoris. No abnormalities in $\mathrm{Mg}$ content were observed in intact or TPTX dystrophic hamsters. Ether-extractable fat of the heart and diaphragm was reduced in dystrophic hamsters and was not modified by TPTX. Protein synthesis was enhanced in the diaphragm of dystrophic hamsters but was not changed by TPTX. The concentration of CPK in plasma was elevated in dystrophic hamsters and fell significantly after TPTX. In the latter animals, microscopic examination of the heart showed
\end{abstract}

Portions of this work were presented at the 62nd Annual Meeting of the Endocrine Society, Washington, D. C., 18 June 1980. Part of the data reported herein was obtained in partial fulfillment of the requirements of Ph.D. degree of Dr. Bhattacharya at Memphis State University.

Address reprint requests to Dr. Palmieri, University of Tennessee.

Received for publication 14 July 1980 and in revised form 7 April 1981. lesser signs of dystrophy, particularly in the degree of fibrosis.

To determine the degree of dystrophy at the age when TPTX was performed, identical analyses were made in 35-d-old hamsters. Definitive histological signs of dystrophy were observed, and although the Ca content in heart, diaphragm, and rectus femoris was elevated, the values were lower than in 90-d-old intact and TPTX dystrophic hamsters. This indicates that chronic TPTX in dystrophic hamsters reduces, but does not arrest, the dystrophic process.

In normal hamsters, a $50 \%$ reduction in plasma $\mathrm{Ca}$ concentration was observed $6 \mathrm{~h}$ after TPTX; $55 \mathrm{~d}$ after TPTX, however, plasma Ca was within normal limits in both normal and dystrophic hamsters. No parathyroid tissue was observed in serial sections of the trachea and adjacent tissues in TPTX animals. This suggests that in chronically TPTX hamsters fed a standard laboratory diet, plasma $\mathrm{Ca}$ can be maintained by mechanisms independent of parathyroid function.

The data indicate that in dystrophic hamsters TPTX causes a marked reduction in: $(a)$ muscle $\mathrm{Ca}$ accumulation, (b) levels of plasma CPK and, $(c)$ intensity of histological changes in the heart. These changes were independent of the levels of plasma $\mathrm{Ca}$ and were not observed in normal hamsters. We conclude that PTH accentuates the dystrophic process, probably by enhancing the already increased $\mathrm{Ca}$ flux into muscle (apparently caused by defective sarcolemma). We postulate that normal secretion of PTH may have a deleterious effect in congenital or acquired conditions associated with altered plasma membranes.

\section{INTRODUCTION}

Excessive $\mathrm{Ca}$ accumulation in muscle, which occurs in genetic (1), nutritional $(2,3)$, and drug-induced muscu- 
lar dystrophy (4), appears to play an important pathophysiological role in the dystrophic process (5-7). There is cumulative evidence indicating that in $\mathrm{Du}$ chenne muscular dystrophy, the most severe type of human muscular dystrophy, there is a defect in plasma membrane of muscle $(8,9)$ and erythrocytes (10). A similar defect was observed in muscle of dystrophic hamsters (11). This defect may explain, at least in part, the leak of intracellular substances, such as creatine phosphokinase (CPK), ${ }^{1}$ to the extracellular environment, and the excessive incorporation of extracellular components such as $\mathrm{Ca}$ inside the cell $(7,12-14)$. Because it has been estimated that the concentration of extracellular $\mathrm{Ca}$ is $\sim 1 \mathrm{mM}$ and $0.1 \mu \mathrm{M}$ in the intracellular compartment (15), it is likely that a defect in plasma membrane physiology, such as decreased effectiveness of the membrane Ca pump or an increase in passive $\mathrm{Ca}$ permeability, could be responsible for the elevated $\mathrm{Ca}$ content in dystrophic muscle.

Parathyroid hormone (PTH) increases the flux of Ca into the cytosol of cells (16) both directly by altering plasma membrane permeability and indirectly by increasing intracellular cyclic AMP, which in turn stimulates the flux of $\mathrm{Ca}$ from mitochondria into the cytosol (17). In hyperparathyroidism there is an abnormal accumulation of $\mathrm{Ca}$ in soft tissues (18). This effect is independent of the concentration of $\mathrm{Ca}$ in plasma. Increased $\mathrm{Ca}$ content was found in brain (19) and in muscle $(20)$ of uremic dogs with secondary hyperparathyroidism and having normal or low plasma Ca. Parathyroidectomy prevented, and administration of PTH to parathyroidectomized uremic dogs reproduced, the abnormal accumulation of $\mathrm{Ca}$ in these tissues $(19,20)$.

The preceding prompted our hypothesis that in the presence of altered plasma membranes, as occurs in muscular dystrophy, "normal" levels of circulating PTH could enhance the accumulation of $\mathrm{Ca}$ in muscle, resulting in cellular damage and accentuation of the dystrophic process. To test this hypothesis, the chronic effect of surgical ablation of the parathyroid glands on muscle $\mathrm{Ca}, \mathrm{Mg}$, protein synthesis, and histology, as well as plasma $\mathrm{CPK}, \mathrm{Ca}$, and $\mathrm{Mg}$, were studied in dystrophic and normal hamsters.

\section{METHODS}

Dystrophic hamsters (BIO 14.6 strain) and nondystrophic hybrid hamsters of the same age (BIO F1B strain), $35 \mathrm{~d}$, were purchased from Bio-Research Consultants, Inc., Cambridge, Mass., and shipped to Hormone Assay Laboratory, Chicago, Ill., for thyroparathyroidectomy (TPTX). $3 \mathrm{~d}$ after surgery,

\footnotetext{
${ }^{1}$ Abbreviations used in this paper: CPK, creatine phosphokinase; DH, dystrophic hamsters; NH, normal hamsters; PTH, parathyroid hormone; TPTX, thyroparathyroidectomy.
}

the animals were shipped to our laboratory, housed in groups of five, and fed Rodent Laboratory Chow 5001 (Ralston Purina Co., St. Louis, Mo.), containing $12 \mathrm{~g}$ of $\mathrm{Ca}$ and $8 \mathrm{~g}$ of $\mathrm{P} / \mathrm{kg}$ ration, and tap water ad lib. A replacement dose of L-thyroxine, $0.6 \mu \mathrm{g} / 100 \mathrm{~g}$ body $\mathrm{wt} / \mathrm{d}$, was given to TPTX hamsters. The thyroxine (Sigma Chemical Co., St. Louis, Mo.) was dissolved in slightly alkaline-distilled water, diluted with $0.4 \mathrm{~g} / \mathrm{dl}$ bovine serum albumin in $0.15 \mathrm{M} \mathrm{NaCl}, \mathrm{pH} 7.0$, to a concentration of $3 \mu \mathrm{g} / \mathrm{ml}$, and frozen in aliquots. Each day a new vial was thawed, and $0.2 \mathrm{ml} / 100 \mathrm{~g}$ body wt was injected subcutaneously in the neck. Intact animals received $0.15 \mathrm{M}$ $\mathrm{NaCl}, 0.2 \mathrm{ml} / 100 \mathrm{~g}$ body $\mathrm{wt} / \mathrm{d}$. The dose of L-thyroxine used is known to be adequate for maintaining euthyroid status in thyroidectomized hamsters (21). $55 \mathrm{~d}$ after TPTX (age $90 \mathrm{~d}$ ), the animals were anesthetized with ether, and blood was drawn from the abdominal aorta with heparinized syringes for separation of plasma at $4^{\circ} \mathrm{C}$. Plasma was frozen at $-70^{\circ} \mathrm{C}$ for later determination of $\mathrm{CPK}, \mathrm{Ca}$, and $\mathrm{Mg}$. Diaphragm muscle was removed from the rib cage; one-fourth was taken for histology, and one-half for determining $\mathrm{Ca}$ and $\mathrm{Mg}$. The remaining quarter diaphragm was weighed and used to measure the rate of protein synthesis in vitro. The heart was cleaned of adjacent tissues. The ventricles were weighed, the apex was used for histology, and the remainder of the ventricles were used to measure $\mathrm{Ca}$ and $\mathrm{Mg}$. Finally, the left rectus femoris was removed, freed of visible fat and fascia, analyzed for $\mathrm{Ca}$ and $\mathrm{Mg}$ content, and mounted for histological examination. To determine the completeness of the TPTX, a careful examination of the trachea and adjacent area was performed under a dissecting microscope, and in addition, the trachea and adjacent tissues were fixed in $10 \%$ neutral formalin for histological evaluation.

Quarter-diaphragms were incubated at $37^{\circ} \mathrm{C}$ for $1 \mathrm{~h} \mathrm{in} 6 \mathrm{ml}$ of Krebs-Ringer bicarbonate buffer containing $50 \mu \mathrm{M}$ Lphenylalanine-2,3-3 $\mathrm{H}$ (New England Nuclear, Boston, Mass.), $1 \mu \mathrm{Ci} / \mathrm{ml}$. The tissues were then processed as described (22), and the incorporation of phenylalanine into protein was expressed as disintegrations per minute ${ }^{3} \mathrm{H}$ per milligram protein.

For histological examination of muscle, samples of the heart, diaphragm, and rectus femoris were immediately mounted in tragacanth gum and frozen in 2-methylbutane that had been chilled in liquid nitrogen (23). Sections (10 $\mu \mathrm{m})$ were stained with hematoxylin-eosin, modified Gomori trichrome (23), oil red $O(23)$, and alizarin red $S$ (24). All muscle specimens were labeled using a randomized code to ensure a blind histological evaluation. An arbitrary scale of 0-4 was used for each parameter examined; 0 represented absence of lesions, and $\mathbf{4}$ indicated severe involvement.

Chemical analyses of tissues were conducted in dry, defatted specimens digested with $0.75 \mathrm{~N}$ nitric acid at $68^{\circ} \mathrm{C}$ for $15 \mathrm{~h}$ as described (25). This procedure extracts $99.8 \%$ of $\mathrm{Ca}$ and $\mathrm{Mg}$ from muscle. Determinations of $\mathrm{Ca}$ and $\mathrm{Mg}$ in tissues and plasma were done using atomic absorption spectrophotometry using a stoichiometric nitrous oxideacetylene flame for atomization $(25,26)$. This procedure causes higher atomization for $\mathrm{Ca}(27)$, and therefore is more sensitive, offers less fluctuation in the results, and has higher reproducibility than the air-acetylene flame conventionally used for atomization. An estimate of neutral fat content was obtained by the decrease in dry weight of the tissues after extraction with diethyl ether (25).

Plasma CPK was assayed with a kit from Sigma Chemical Co., (45-UV), and the results were expressed in Sigma units per milliliter.

To determine the "base-line" values at the age when TPTX was performed, groups of BIO 14.6 dystrophic and BIO F1B nondystrophic hamsters were sent directly from Bio-Research 
TABLE I

Fat, $\mathrm{Ca}$, and Mg Content in the Heart (Ventricles) of Intact and Chronically TPTX NH and DH, Age $90 \mathrm{~d}$

\begin{tabular}{|c|c|c|c|c|}
\hline \multicolumn{2}{|l|}{ Group $(n)$} & \multirow{2}{*}{$\begin{array}{c}\text { Neutral lipid } \\
\text { g/100 g } \\
\text { dry tissue }\end{array}$} & $\mathrm{Ca}$ & \multirow{2}{*}{$\frac{\mathrm{Mg}}{\mathrm{free}}$} \\
\hline & & & $\begin{array}{c}\text { meq/kg fat-free } \\
\quad \text { dry tissue }\end{array}$ & \\
\hline NH (6) & $\begin{array}{l}\text { Mean } \\
\pm \text { SE }\end{array}$ & $\begin{array}{l}9.13 \\
0.21\end{array}$ & $\begin{array}{r}19.90 \\
0.10\end{array}$ & $\begin{array}{r}81.06 \\
0.24\end{array}$ \\
\hline $\mathrm{NH}+\operatorname{TPTX}(5)$ & $\begin{array}{l}\text { Mean } \\
\pm \mathrm{SE} \\
P\end{array}$ & $\begin{array}{r}11.41 \\
1.93 \\
\text { NS }\end{array}$ & $\begin{array}{r}19.62 \\
0.50 \\
\text { NS }\end{array}$ & $\begin{array}{c}84.77 \\
0.94 \\
<0.005\end{array}$ \\
\hline $\mathrm{DH}(10)$ & $\begin{array}{l}\text { Mean } \\
\pm \mathrm{SE}\end{array}$ & $\begin{array}{l}5.39 \\
0.36\end{array}$ & $\begin{array}{r}414.01 \\
36.99\end{array}$ & $\begin{array}{r}86.47 \\
2.32\end{array}$ \\
\hline $\mathrm{DH}+\operatorname{TPTX}(9)$ & $\begin{array}{l}\text { Mean } \\
\pm \text { SE } \\
P\end{array}$ & $\begin{array}{c}6.02 \\
0.57 \\
\text { NS }\end{array}$ & $\begin{array}{c}199.56 \\
17.43 \\
<0.0001\end{array}$ & $\begin{array}{c}86.61 \\
0.75 \\
\text { NS }\end{array}$ \\
\hline & $P^{*}$ & $<0.0001$ & $<0.0001$ & $<0.05$ \\
\hline
\end{tabular}

Each $P$ value obtained by $t$ test compares intact vs. TPTX animals.

${ }^{*} P$ value compares intact $\mathrm{NH}$ with intact $\mathrm{DH}$.

Consultants to our laboratory, killed at age $35 \mathrm{~d}$, and analyzed as were the older hamsters.

A study of the acute effect of TPTX on plasma calcium in hamsters was performed as follows: 12 BIO F1B normal hamsters, age $35 \mathrm{~d}$, were shipped from Bio-Research Consultants to Hormone Assay Laboratory. Six animals were submitted to TPTX, and six were sham operated. Immediately after surgery, the animals were shipped to our laboratory. Upon arrival, $6 \mathrm{~h}$ after surgery, plasma calcium was determined in blood drawn from the abdominal aorta as described above.

Data on $\mathrm{Ca}$ and $\mathrm{Mg}$ content, and protein synthesis were subjected to 2-factor analysis of variance (ANOVA). When necessary to achieve homogeneity of variance, the data were $\log$ normalized. Comparisons between groups were made using Newman-Keuls or multiple $t$ tests (28).

\section{RESULTS}

\section{Effects of chronic TPTX}

Dystrophic and normal hamsters showed excellent tolerance to the chronic effects of TPTX. There were no signs of neuromuscular irritability, and therefore no additional $\mathrm{Ca}$ or vitamin $\mathrm{D}$ was given to that already present in the standard diet. The weight gain and general behavior were identical in intact and TPTX animals.

\section{HEART}

Fat, Ca, and Mg content. As shown in Table I, the $\mathrm{Ca}$ content in the ventricles of dystrophic hamsters (DH) was $\sim 20$ times higher than in normal hamsters (NH). TPTX significantly $(P<0.001)$ reduced the $\mathrm{Ca}$ content in $\mathrm{DH}$ by half, but had no effect in $\mathrm{NH}$. The $\mathrm{Mg}$ content was only slightly elevated in DH and did not change after TPTX. In NH however, TPTX provoked a mild (5\%) but significant elevation of $\mathrm{Mg}(P<0.005)$. Neutral lipid, expressed as g per $100 \mathrm{~g}$ of dry tissue, was lower in DH than in NH $(P<0.0001)$, but was not modified by TPTX (Table I).

Histological examination (Table II). No lesions were observed in NH, intact, or TPTX hamsters. In $\mathrm{DH}$, phagocytosis was frequently found, with foci of mononuclear cells around necrotic fibers and areas of calcium precipitation demonstrated by alizarin red $S$ (Fig. 1) and hematoxylin-eosin stains. Frequent disruption and hyalinization of myocardial fibers, which were sometimes replaced by bands of fibrotic tissue, were observed (Fig. 2); fat accumulation was not striking and was evident only in scattered areas. Although TPTX resulted in an overall reduction in the intensity of the lesions in DH, only the degree of fibrosis was significantly reduced by TPTX.

\section{Diaphragm}

Fat, Ca, and Mg content (Table III). Although the changes in $\mathrm{Ca}$ content were less than in the heart, the diaphragm of DH still had seven times more Ca than $\mathrm{NH}$, and, as observed in the heart, TPTX reduced the $\mathrm{Ca}$ content in DH $(P<0.05)$. The content of $\mathrm{Mg}$ was almost identical in all groups, and the fat content was lower in DH than in NH $(P<0.001)$.

Protein synthesis. At the time of sacrifice, $90 \mathrm{~d}$, the diaphragm of DH had visible hypertrophy in com-

TABLE II

Histological Findings in the Heart of Intact and Chronically TPTX DH, Age $90 \mathrm{~d}$

\begin{tabular}{lcccc}
\hline \multicolumn{1}{c}{ Group $(n)$} & Necrosis & Phagocytosis & Ca & Fibrosis \\
\hline DH $(10)$ & $1.55 \pm 0.17$ & $2.25 \pm 0.34$ & $2.34 \pm 0.17$ & $2.65 \pm 0.20$ \\
DH + TPTX (9) & $1.17 \pm 0.14$ & $2.00 \pm 0.20$ & $1.83 \pm 0.28$ & $1.80 \pm 0.14$ \\
$P$ & $N S$ & $N S$ & $N S$ & $<0.01$ \\
\hline
\end{tabular}

Mean $\pm \mathrm{SE}$ of values obtained using a $0 \rightarrow 4$ scale; 0 represents absence of lesions and 4 represents severe involvement. All intact and TPTX NH were 0 . Note the lack of difference in observed $\mathrm{Ca}$ deposits, in spite of a $50 \%$ reduction in chemical analysis of $\mathrm{Ca}$ in TPTX hamsters (Table I). 


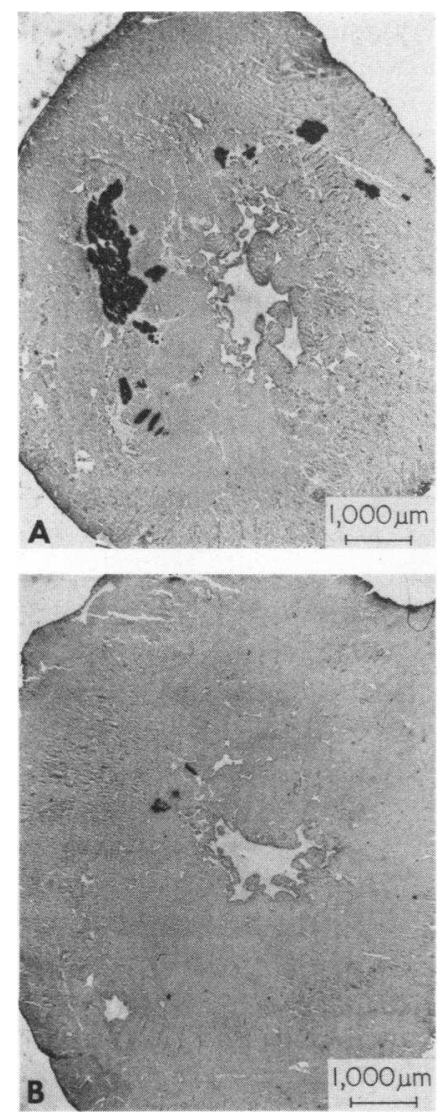

Figure 1 Histology of the heart, ventricular level, low magnification, stained with alizarin red S. Larger areas of calcium deposits are observed in intact (A) than in TPTX (B) DH; in the majority of DH + TPTX, however, this difference was less noticeable (Table II).

parison with $\mathrm{NH}$, and the rate of protein synthesis was greater $(P<0.002)$ than in NH (Table IV). TPTX (with replacement of thyroxine) had no significant effect on the rate of protein synthesis in either $\mathrm{NH}$ or $\mathrm{DH}$.

Histological examination. Diaphragm from $\mathrm{DH}$ showed many internalized nuclei, variation in fiber size, mildly increased endomysial connective tissue, and many necrotic fibers, some of which were undergoing phagocytosis; in some areas phagocytosis was marked. Occasional fibers showed increased calcium staining. Calcium precipitates were uncommon and only minimal. No significant difference in the diaphragm of DH + TPTX was observed in relation to intact DH (data not shown).

\section{RECTUS FEMORIS}

Fat, $\mathrm{Ca}$, and $\mathrm{Mg}$ content. The chemical analysis of rectus femoris showed three times more $\mathrm{Ca}$ in $\mathrm{DH}$ than in NH (Table V). In DH + TPTX, the Ca content was lower $(P<0.05)$ than in DH. No difference between TPTX and intact NH was observed. No sig-
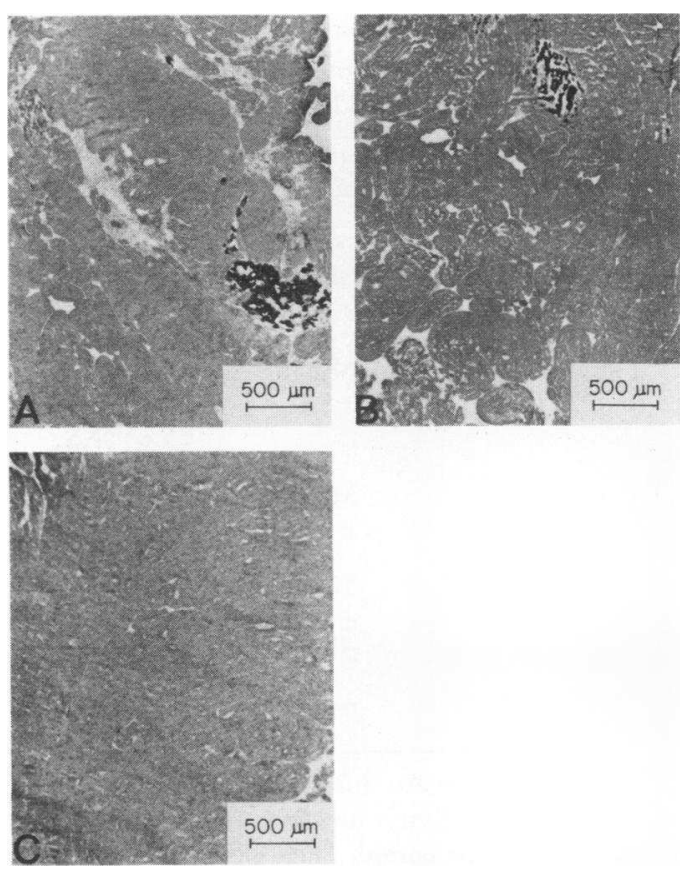

FIGURE 2 Histology of the heart, ventricular level, higher magnification, hematoxylin-eosin stain. (A) Excessive fibrosis, tissue disruption, and calcium accumulation are present in an intact DH. (B) Decreased fibrosis and less calcium accumulation are observed in a DH + TPTX. (C) NH.

nificant differences in the contents of $\mathrm{Mg}$ or fat were observed between any of the groups.

Histological examination (Table VI). Dystrophic muscle showed many internalized nuclei. Occasional

TABLE III

Fat, Ca, and Mg Content in the Diaphragm of Intact and Chronically TPTX NH and DH, Age $90 \mathrm{~d}$

\begin{tabular}{|c|c|c|c|c|}
\hline \multicolumn{2}{|l|}{ Group (n) } & \multirow{2}{*}{$\begin{array}{c}\text { Neutral lipid } \\
\begin{array}{c}\text { g/100 g dry } \\
\text { tissue }\end{array}\end{array}$} & \multirow{2}{*}{\multicolumn{2}{|c|}{$\begin{array}{l}\mathrm{Ca} \quad \mathrm{Mg} \\
\begin{array}{c}\text { meq/kg fat-free } \\
\text { dry tissue }\end{array}\end{array}$}} \\
\hline & & & & \\
\hline \multirow[t]{2}{*}{ NH (6) } & Mean & 8.04 & 11.30 & 83.66 \\
\hline & $\pm \mathrm{SE}$ & 0.56 & 0.16 & 0.57 \\
\hline \multirow[t]{3}{*}{$\mathrm{NH}+\mathrm{TPTX}(5)$} & Mean & 8.68 & 11.49 & 83.98 \\
\hline & $\pm \mathrm{SE}$ & 0.24 & 0.17 & 1.61 \\
\hline & $P$ & NS & NS & NS \\
\hline \multirow[t]{2}{*}{ DH (10) } & Mean & 4.96 & 80.63 & 85.66 \\
\hline & $\pm \mathrm{SE}$ & 0.42 & 6.61 & 0.68 \\
\hline \multirow[t]{4}{*}{$\mathrm{DH}+\mathrm{TPTX}(9)$} & Mean & 5.27 & 60.58 & 84.86 \\
\hline & $\pm \mathrm{SE}$ & 0.39 & 2.72 & 0.67 \\
\hline & $P$ & NS & $<0.05$ & NS \\
\hline & $P^{*}$ & $<0.0005$ & $<0.0001$ & $<0.05$ \\
\hline
\end{tabular}

Each $P$ value obtained by $t$ test compares intact vs. TPTX animals.

* $P$ value compares intact $\mathrm{NH}$ with intact $\mathrm{DH}$. 
TABLE IV

Incorporation of Phenylalanine into Protein by Diaphragms of Intact and Chronically TPTX NH and DH, Age $90 \mathrm{~d}$

\begin{tabular}{clc}
\hline Group (n) & & Incorporation \\
\hline & & $d p m$ ' H/mg protein \\
NH (6) & Mean & 6414 \\
& \pm SE & 767 \\
NH + TPTX (5) & Mean & 4917 \\
& \pm SE & 406 \\
& $P$ & NS \\
DH (10) & Mean & 8723 \\
& \pm SE & 770 \\
DH + TPTX (9) & Mean & 8101 \\
& \pm SE & 585 \\
& $P$ & NS \\
& $P *$ & $<0.002$ \\
\hline
\end{tabular}

Quarter-diaphragms were incubated $1 \mathrm{~h}$ with $\left[{ }^{3} \mathrm{H}\right]$ phenylalanine, and radioactivity incorporated into purified total tissue protein was measured. Data were log normalized and subjected to two-way analysis of variance, which showed that DH $(n=19)$ had a greater rate of protein synthesis than NH $(n=11)$, but that TPTX $(n=14)$ had no effect. There was no interaction between factors, "dystrophy" and "TPTX".

Each $P$ value obtained by $t$ test compares intact vs. TPTX animals.

${ }^{*} \boldsymbol{P}$ value compares all $\mathrm{NH}$ with all $\mathrm{DH}$, by 2 -factor analysis of variance.

TABLE V

Fat, Ca, and Mg Content in the Rectus Femoris of Intact and Chronically TPTX NH and DH, Age $90 \mathrm{~d}$

\begin{tabular}{|c|c|c|c|c|}
\hline \multicolumn{2}{|l|}{ Group $(n)$} & \multirow{2}{*}{$\begin{array}{c}\text { Neutral lipid } \\
\begin{array}{c}\text { g/loo g dry } \\
\text { tissue }\end{array}\end{array}$} & $\mathrm{Ca}$ & $\mathrm{Mg}$ \\
\hline & & & \multicolumn{2}{|c|}{$\begin{array}{l}\text { meq/kg fat-free dry } \\
\text { tissue }\end{array}$} \\
\hline $\mathrm{NH}(6)$ & $\begin{array}{l}\text { Mean } \\
\pm \text { SE }\end{array}$ & $\begin{array}{l}3.65 \\
0.43\end{array}$ & $\begin{array}{r}14.83 \\
0.32\end{array}$ & $\begin{array}{r}74.58 \\
2.86\end{array}$ \\
\hline $\mathrm{NH}+\mathrm{TPTX}(5)$ & $\begin{array}{l}\text { Mean } \\
\pm \mathrm{SE} \\
P\end{array}$ & $\begin{array}{l}3.01 \\
0.40 \\
\text { NS }\end{array}$ & $\begin{array}{c}15.13 \\
0.94 \\
\text { NS }\end{array}$ & $\begin{array}{c}80.95 \\
2.47 \\
\text { NS }\end{array}$ \\
\hline DH (10) & $\begin{array}{l}\text { Mean } \\
\pm \mathrm{SE}\end{array}$ & $\begin{array}{l}3.06 \\
0.37\end{array}$ & $\begin{array}{r}50.60 \\
9.50\end{array}$ & $\begin{array}{r}77.41 \\
2.92\end{array}$ \\
\hline $\mathrm{DH}+\mathrm{TPTX}(9)$ & $\begin{array}{l}\text { Mean } \\
\pm S E \\
P\end{array}$ & $\begin{array}{l}3.33 \\
0.45 \\
\text { NS }\end{array}$ & $\begin{array}{r}28.81 \\
2.86 \\
<0.05\end{array}$ & $\begin{array}{c}77.38 \\
1.76 \\
\text { NS }\end{array}$ \\
\hline & $P^{*}$ & NS & $<0.002$ & NS \\
\hline
\end{tabular}

Each $P$ value obtained by $t$ test compares intact vs. TPTX animals.

* $P$ value compares intact $\mathrm{NH}$ with intact $\mathrm{DH}$.
TABLE VI

Histological Findings in the Rectus Femoris of Intact and Chronically TPTX DH, Age $90 \mathrm{~d}$

\begin{tabular}{lccc}
\hline \multicolumn{1}{c}{ Lesion } & DH $(n=10)$ & DH + TPTX $(n=9)$ & $P$ \\
\hline Atrophy & $2.30 \pm 0.13$ & $1.44 \pm 0.28$ & $<0.02$ \\
Necrosis & $1.55 \pm 0.20$ & $1.61 \pm 0.30$ & NS \\
Phagocytosis & $2.65 \pm 0.18$ & $2.33 \pm 0.38$ & NS \\
Internal nuclei & $3.10 \pm 0.18$ & $2.67 \pm 0.14$ & NS \\
Fibrosis & $0.45 \pm 0.18$ & $0.55 \pm 0.29$ & NS \\
Regeneration & $2.45 \pm 0.21$ & $2.17 \pm 0.20$ & NS \\
Calcium & $1.45 \pm 0.20$ & $1.28 \pm 0.18$ & NS \\
\hline
\end{tabular}

Mean \pm SE of values obtained using a $0 \rightarrow 4$ scale; 0 represents absence of lesions and 4 severe involvement. All intact and TPTX NH were 0.

vesicles were seen in regenerating fibers. There was great variation in muscle fiber size, with atrophic and hypertrophic fibers; some hypertrophic fibers were splitting. Necrosis with phagocytosis was also evident, which at times appeared in foci. Some overcontracted fibers with $\mathrm{Ca}$ accumulation were also seen. Rarely, Ca precipitates were seen in the interstitium. Connective tissue and fat accumulation were only minimally increased. In DH + TPTX there was reduction in the number of atrophic fibers $(P<0.02)$, but no other major changes occurred.

\section{Plasma}

Plasma CPK was elevated considerably in DH (Table VII) and was reduced $\sim 65 \%$ in DH + TPTX $(P<0.02)$.

TABLE VII

$\mathrm{Ca}, \mathrm{Mg}$, and CPK in the Plasma of Intact and Chronically TPTX NH and DH, Age $90 \mathrm{~d}$

\begin{tabular}{clccc}
\hline Group $(n)$ & & Ca & Mg & CPK \\
\hline & & $m g / d l$ & meq $l$ & Sigma U/ml \\
NH (6) & Mean & 10.78 & 1.94 & 27.5 \\
& \pm SE & 0.24 & 0.05 & 4.7 \\
NH + TPTX (5) & Mean & 11.42 & 2.04 & 44.5 \\
& \pm SE & 0.31 & 0.06 & 9.0 \\
& $P$ & NS & NS & NS \\
DH (10) & Mean & 10.94 & 1.85 & 1293 \\
& \pm SE & 0.24 & 0.03 & 416 \\
DH + TPTX (9) & Mean & 10.63 & 1.95 & 424 \\
& \pm SE & 0.39 & 0.06 & 67 \\
& $P$ & NS & NS & $<0.02$ \\
& $P *$ & NS & NS & $<0.002$ \\
& & & & \\
& & &
\end{tabular}

Each $P$ value obtained by $t$ test compares intact vs. TPTX animals.

* $P$ value compares intact $\mathrm{NH}$ with intact $\mathrm{DH}$. 
TABLE VIII

Fat, Ca, and Mg Content in the Tissues of Intact NH and DH, Age $35 \mathrm{~d}$

\begin{tabular}{|c|c|c|c|c|}
\hline Tissue & Group $(n)$ & Neutral lipid & $\mathrm{Ca}$ & Mg \\
\hline & & $\mathrm{g} / 100 \mathrm{~g}$ dry tissue & \multicolumn{2}{|c|}{ meq/kg fat-free dry tissue } \\
\hline Heart & $\begin{array}{l}\text { NH (10) } \\
\text { DH (10) } \\
P\end{array}$ & $\begin{array}{c}8.73 \pm 0.09 \\
8.73 \pm 0.05 \\
\text { NS }\end{array}$ & $\begin{array}{c}11.53 \pm 0.09 \\
51.68 \pm 16.73 \\
<0.03\end{array}$ & $\begin{array}{c}90.62 \pm 0.48 \\
90.69 \pm 0.41 \\
\text { NS }\end{array}$ \\
\hline Diaphragm & $\begin{array}{l}\text { NH (10) } \\
\text { DH (10) } \\
P\end{array}$ & $\begin{array}{c}9.23 \pm 0.12 \\
6.59 \pm 0.26 \\
<0.0001\end{array}$ & $\begin{array}{c}11.22 \pm 0.04 \\
33.99 \pm 4.50 \\
<0.0001\end{array}$ & $\begin{array}{c}85.52 \pm 0.73 \\
85.81 \pm 0.52 \\
\text { NS }\end{array}$ \\
\hline Rectus femoris & $\begin{array}{l}\text { NH (10) } \\
\text { DH (10) } \\
P\end{array}$ & $\begin{array}{c}5.72 \pm 0.15 \\
4.93 \pm 0.16 \\
<0.002\end{array}$ & $\begin{array}{c}10.80 \pm 0.07 \\
18.23 \pm 1.95 \\
<0.002\end{array}$ & $\begin{array}{c}77.22 \pm 0.17 \\
77.17 \pm 0.35 \\
\text { NS }\end{array}$ \\
\hline
\end{tabular}

Each $P$ value obtained by $t$ test compares the NH with DH within the same tissue.

Plasma Ca and $\mathrm{Mg}$ were normal in all groups; chronic TPTX had no effect on $\mathrm{Ca}$ and $\mathrm{Mg}$ concentrations.

\section{Muscle status at the age of TPTX, $35 d$}

To determine whether the changes observed in DH + TPTX represented improvement of the muscle, or arrest or retardation of the dystrophic process by parathyroid ablation; fat, mineral content, and histology of the heart, diaphragm, and rectus femoris were determined in $\mathrm{DH}$ and $\mathrm{NH}$, age $35 \mathrm{~d}$, the age when TPTX was performed. As shown in Table VIII, the Ca content in heart, diaphragm, and rectus femoris was elevated in young DH $(P<0.03,<0.0001,<0.002$, respectively). The histological examination of tissues (Table IX) revealed signs compatible with dystrophy, although they were less intense than in animals killed at age $90 \mathrm{~d}$. Thus, the histological findings and the $\mathrm{Ca}$ content suggest that at the time TPTX was performed, there were obvious signs of dystrophy. The comparison of the Ca content in tissues in intact and DH + TPTX, age $90 \mathrm{~d}$ (Tables I, III, and V), with the values ob-

TABLE IX

Histological Findings in the Heart and Rectus Femoris of Intact DH, Age $35 d$

\begin{tabular}{lcc}
\hline \multicolumn{1}{c}{ Lesion } & Heart & Rectus femoris \\
\hline Atrophy & - & $1.25 \pm 0.20$ \\
Necrosis & $0.35 \pm 0.10$ & $0.75 \pm 0.13$ \\
Phagocytosis & $0.35 \pm 0.15$ & $0.75 \pm 0.49$ \\
Calcium & $0.40 \pm 0.25$ & - \\
Internal nuclei & - & $1.45 \pm 1.12$ \\
Fibrosis & $0.70 \pm 0.17$ & $0.05 \pm 0.05$ \\
Regeneration & - & $1.55 \pm 0.40$ \\
\hline
\end{tabular}

Mean \pm SE of values obtained in $10 \mathrm{DH}$ using a $0 \rightarrow 4$ scale; 0 represents absence of lesions and 4 severe involvement. tained in 35-d-old DH (Table VIII) clearly indicates that TPTX retarded the abnormal accumulation of $\mathrm{Ca}$ in $\mathrm{DH}$ but did not prevent it. These findings correlate well with the histological examination of tissues (Tables II, VI, and IX) and suggest that TPTX reduced the intensity of, but did not arrest, the dystrophic process.

The fat content of the diaphragm $(P<0.0001)$ and rectus femoris $(P<0.002)$ was lower in $\mathrm{DH}$ than $\mathrm{NH}$, but was unchanged in the heart (Table VIII). In all tissues studied in $\mathrm{DH}$, the fat content was lower at age $90 \mathrm{~d}$ than at age $35 \mathrm{~d}(P<0.01)$ (Tables I, III, V, and VIII). In NH only the rectus femoris of the older animals showed less fat than at $35 \mathrm{~d}(P<0.001)$ (Tables $\mathrm{V}$ and VIII). In sections of heart, diaphragm, and rectus femoris of all groups of animals, histological staining for lipid revealed no appreciable accumulation of fat.

\section{Effects of acute TPTX}

Although no parathyroid tissue was observed with the dissecting microscope or in serial histological sections of tracheas and adjacent tissues $55 \mathrm{~d}$ after TPTX, the findings of normal plasma Ca in TPTX, normal, and dystrophic hamsters (Table VII) prompted us to study the effect of acute TPTX in NH under identical experimental conditions. Six NH underwent TPTX and six were sham operated and shipped without delay to our laboratory. Two TPTX animals died during shipping. The remaining four TPTX hamsters showed low plasma $\mathrm{Ca}, 5.84 \pm 0.58 \mathrm{mg} / \mathrm{dl}, 6 \mathrm{~h}$ after TPTX. Shamoperated hamsters had normal plasma $\mathrm{Ca}, 10.10 \pm 0.70$ $\mathrm{mg} / \mathrm{dl}$. Plasma Mg was unchanged.

\section{DISCUSSION}

This study clearly demonstrates first that in the BIO 14.6 $\mathrm{DH}$ there is a massive accumulation of $\mathrm{Ca}$ in the 
heart, diaphragm, and rectus femoris that correlates well with the intensity of the histological picture of muscular dystrophy and the levels of CPK in plasma. Secondly, removal of the parathyroid and thyroid glands followed by replacement with physiological doses of thyroxine resulted in: $(a)$ reduction of $\mathrm{Ca}$ accumulation in all three muscles examined, $(b)$ reduction in the levels of CPK in plasma, and (c) mild reduction in fibrosis in the heart and atrophy in the rectus femoris. These effects of TPTX were only observed in DH. In normal hamsters no changes in the Ca content of heart, diaphragm, and rectus femoris occurred; only a mild elevation in the $\mathrm{Mg}$ content of the heart was observed following TPTX. Thus, chronic TPTX causes a reduction in the accumulation of $\mathrm{Ca}$ in muscular dystrophy but has no major effects in normal animals. The chemical analysis and histology of muscle, as well as the plasma CPK levels in 35-d-old DH at the time when TPTX was performed, suggest that TPTX did not arrest or reverse the dystrophic process, but it did retard the progression of the disease.

Parathyroid hormone stimulates the influx of $\mathrm{Ca}$ into the cytosol (16), and excessive secretion or exogenous administration of the hormone results in abnormal $\mathrm{Ca}$ accumulation in soft tissues (18), particularly muscle (20) and brain (19). These effects are observed in the presence $(18)$ or absence $(19,20)$ of hypercalcemia. Moreover, the morphological and functional muscular abnormalities of hypercalcemic primary hyperparathyroidism (29) are also observed in the secondary hyperparathyroidism of osteomalacia with low serum Ca levels (30). It is evident, therefore, that any form of hyperparathyroidism, independent of the levels of plasma $\mathrm{Ca}$, may cause structural, chemical, and functional alterations of muscle.

In human $(7,12,14$, and 31$)$ and hamster $(1,4)$ muscular dystrophy, the increased Ca content appears to occur both intracellularly and extracellularly, the latter probably as a result of necrosis. In the same animal model used in this study, the BIO 14.6 DH, Wrogemann and Nylen (32) found that cardiac mitochondrial $\mathrm{Ca}$ was increased $\sim 75 \%$ above normal. Similarly, Yarom et al. (13), using an electron microscopic x-ray fluorescence technique for elemental microanalysis, observed a $250-300 \%$ increased $\mathrm{Ca}$ in nuclei and sarcoplasm of the heart. Therefore, most of the elevated $\mathrm{Ca}$ content in the heart $(2,000 \%$ increase) observed in our study may represent $\mathrm{Ca}$ deposits, which primarily are extracellular. Our study does not attempt to discern whether TPTX reduced the Ca accumulation in the intracellular space, the interstitium, or both; nevertheless, it is likely that a major part of the reduction in heart $\mathrm{Ca}$ after TPTX occurred extracellularly. This suggests that parathyroid ablation retarded the necrotic process in some manner. One possibility that is consistent with the aforementioned studies of hyperparathyroidism $(18-20)$ and the effects of PTH on isolated heart cells
(33) is that TPTX reduced the flux of Ca into the cells. This accumulation of $\mathrm{Ca}$ has been postulated, on the basis of a variety of experimental approaches, to play an important pathophysiological role in the progression of the dystrophic process (1-7). Further, a $\mathrm{Ca}^{++}$-activated neutral protease recently found in muscle $(34,35)$ may play an important role in muscular dystrophy $(36,37)$. Agents such as leupeptin, which inhibits the $\mathrm{Ca}^{++}$-activated protease (38), appear to have a beneficial effect in some animal models of muscular dystrophy $(39,40)$. Thus, increased cytosolic $\mathrm{Ca}^{++}$, occurring before the development of clearly evident $\mathrm{Ca}$ deposits by light microscopy, could be responsible for some of the multiple changes that characterize the dystrophic process.

In this study, the Ca content in the heart of dystrophic animals was approximately eight times higher than in the rectus femoris, probably due to the more numerous Ca deposits observed in the heart. After TPTX, however, a similar reduction in Ca content $(\sim 50 \%)$ was observed in both tissues, accompanied by some amelioration of the histological picture and fall in the elevated plasma CPK, suggesting a general beneficial effect of parathyroid ablation in the course of the myopathy.

It must be pointed out that most of the work done in the past, as well as the data presented herewith, have been obtained in diverse animal models with muscular dystrophy. There are significant differences in the histological picture, evolution, and severity of the involvement of various types of muscles in animals with muscular dystrophy. None of the available models fully reproduces the human condition. Nevertheless, it is apparent that muscular dystrophy is associated with an increased accumulation of $\mathrm{Ca}$ in muscle $(1-4,7,12-14,31,32)$, and that maneuvers directed to reduce the $\mathrm{Ca}$ flux into cells may have a beneficial influence in the progression of the dystrophic process.

The observation of significant reduction in muscle Ca in TPTX dystrophic hamsters having normal plasma Ca strongly suggests that changes in the circulating Ca concentration were not responsible for the effects observed in TPTX dystrophic hamsters. This finding is in agreement with the reported increased Ca content in brain (19) and muscle (20) in secondary hyperparathyroidism. In Duchenne muscular dystrophy, serum levels of PTH are within normal limits (unpublished observation) ${ }^{2}$ and very likely this is also true in $\mathrm{DH}$, because serum $\mathrm{Ca}$ is normal. It is reasonable to conclude, therefore, that the effects observed in DH + TPTX were due to the removal of the parathyroid glands

\footnotetext{
${ }^{2}$ Serum PTH measured by radioimmunoassay using an antibody that detects predominantly the C-terminal portion of the molecule (48) was $6.0 \pm 1.14 \mu \mathrm{leq} \mathrm{HPTH} / \mathrm{ml}$ in five children with DMD. Normal values in the same assay were 1-7 $\mu$ leq HPTH/ml.
} 
and not to changes in plasma $\mathrm{Ca}$. The in situ examination of the trachea and adjacent tissues, the histological serial section of these tissues, and the expected acute hypocalcemia following TPTX (41) strongly suggest that the excision of the thyroid and parathyroid glands was complete. Although the possibility that aberrant parathyroid tissue remained in the thymus or mediastinum after TPTX cannot be ruled out, the presence of a normal plasma Ca concentration $55 \mathrm{~d}$ after TPTX in $\mathrm{NH}, \mathrm{DH}$, and the lack of the phosphaturic response to PTH in hamsters $(41,42)$ suggests the presence of as yet undefined mechanisms for $\mathrm{Ca}$ and $\mathrm{P}$ homeostasis independent of parathyroid function in this species.

Because TPTX animals received maintenance doses of thyroxine at the apparent daily secretion rate (21) and because the other hormone (calcitonin) secreted by the thyroid inhibits $\mathrm{Ca}$ flux at the cellular level (43), removal of the thyroid should, if anything, have resulted in greater accumulation of $\mathrm{Ca}$ in muscle instead of the observed reduction in muscle $\mathrm{Ca}$ content in DH + TPTX.

Neutral lipid was considerably reduced in the heart of 90-d-old, but not 35-d-old, DH. Quite similar results were obtained by Barakat et al. (44) in cardiomyopathic hamsters of the B10 82.62 strain, which was derived from the B10 14.6 strain used in our study. In agreement with others (11), we failed to find fat accumulation in skeletal muscle of either 35- or 90-d-old DH. In fact, the diaphragm showed marked reduction in neutral lipid at both ages. The decreased neutral lipid seen in the heart and diaphragm can partially be accounted for by the hypertrophy of these tissues $(45,46)$, because our data were expressed as grams of lipid per $100 \mathrm{~g}$ dry weight. It is also conceivable that the increased protein synthesis and degradation (46) observed in DH or the need for increased energy by membrane "pumps" that are attempting to restore ionic balance in the face of leaky cell membranes (47) may increase the utilization of substrate and thus reduce fat accumulation. Our observation of increased protein synthesis in the diaphragm of dystrophic hamsters confirms previous reports of this strain of hamsters (46). This increase was not modified by TPTX. One explanation for this is that protein synthesis in muscular dystrophy may be independent of changes in cellular Ca flux. A more likely explanation, however, is that the increased protein synthesis is largely due to activity of regenerating fibers and that regeneration is unaffected by TPTX. This explanation is also consistent with the histological observation of skeletal muscle in these animals.

Interestingly, we found that in normal hamsters the $\mathrm{Ca}$ content of the heart in 35-d-old animals was lower $(P<0.0001)$ and $\mathrm{Mg}$ was higher $(P<0.0001)$ than in 90-d-old animals. It is conceivable that the effectiveness of the cellular Ca pump may decrease with aging. Systematic studies of this problem may provide new insights on the role of divalent cations in aging.
On the basis of our observations, it seems justified to conclude that PTH, albeit in normal concentrations, exacerbates the dystrophic process in B1O 14.6 polymyopathic hamsters. Because muscular dystrophy in man and animal models is characterized by defective membranes, it would be important to determine whether normal blood levels of PTH may also accentuate $\mathrm{Ca}$ accumulation and aggravate other conditions characterized by accumulation of $\mathrm{Ca}$ in muscle and in which a defective Ca pumping mechanism may occur, such as rhabdomyolysis and malignant hyperthermia.

\section{ACKNOWLEDGMENTS}

The authors wish to thank Ms. Abbie Hinton, Ms. Clarice White, and Ms. Barbara Baker for their skillful technical assistance.

This work was supported in part by the following grants from the National Institutes of Health: U. S. Public Health Service RR05423, RR002211, and CA20939; by the National Science Foundation under grant PCM76-81901; by institutional funds at St. Jude Children's Research Hospital; and by a Memphis State University Research Foundation Fellowship to Dr. Bhattacharya.

\section{REFERENCES}

1. Wrogemann, K., B. E., Jacobson, and M. C. Blanchaer. 1973. On the mechanism of a calcium-associated defect of oxidative phosphorylation in progressive muscular dystrophy. Arch. Biochem. Biophys. 159: 267-278.

2. Godwin, K. O., J. Edwardly, and C. N. Fuss. 1975. Retention of ${ }^{45} \mathrm{Ca}$ in rats and lambs associated with the onset of nutritional muscular dystrophy. Aust. J. Biol. Sci. 28: 457-464.

3. Oldfield, J. E., W. W. Ellis, and O. H. Muth. 1958. White muscle disease (myopathy) in lambs and calves III. Experimental production in calves from cows fed alfalfa hay. J. Am. Vet. Med. Assoc. 132: 211-214.

4. Lossnitzer, K., J. Janke, B. Hein, M. Stauch, and A. Fleckenstein. 1975. Disturbed myocardial calcium metabolism: a possible pathogenetic factor in the hereditary cardiomyopathy of the Syrian hamster. In Recent Advances in Studies on Cardiac Structure and Metabolism. A. Fleckenstein and G. Rona, editors. University Park Press, Baltimore. 6: 207-217.

5. Wrogemann, K., and S. D. J. Pena. 1976. Mitochondrial calcium overload: a general mechanism for cell-necrosis in muscle diseases. Lancet I 672-673.

6. Ebashi, S., and H. Sugita. 1979. The role of calcium in physiological and pathological processes of skeletal muscle. In Current Topics in Nerve and Muscle Research. A. J. Aguayo and G. Karpati, editors. Excerpta Medica, Amsterdam. I. C. S. No. 455. 73-84.

7. Oberc, M. A., and W. K. Engel. 1977. Ultrastructural localization of calcium in normal and abnormal skeletal muscle. Lab. Invest. 36: 566-577.

8. Mokri, B., and A. G. Engel. 1975. Duchenne dystrophy: electron microscopic findings pointing to a basic or early abnormality in the plasma membrane of the muscle fiber. Neurology. 25: 1111-1120.

9. Roses, A. D., M. H. Herbstreith, and S. H. Appel. 1975. Membrane protein kinase alteration in Duchenne muscular dystrophy. Nature (Lond.). 254: 350-351.

10. Araki, S., and S. Mawatari. 1971. Ouabain and erythrocyte-ghost adenosine triphosphatase. Arch. Neurol. 24: 187-190. 
11. Mendel, J. R., R. Higgins, Z. Sahenk, and E. Cosmos. 1979. Relevance of genetic animal models of muscular dystrophy to human muscular dystrophies. Ann. N. Y. Acad. Sci. 317: 409-430.

12. Bodensteiner, J. B., and A. G. Engel. 1978. Intracellular calcium accumulation in Duchenne dystrophy and other myopathies: a study of 567,000 muscle fibers in 114 biopsies. Neurology. 28: 439-446.

13. Yarom, R., I. Friedman, and T. A. Hall. 1977. Calcium and chloride content in myocardium-trapped erythrocytes of cardiomyopathic hamsters. Isr. J. Med. Sci. 13: 12221225.

14. Maunder-Sewry, C. A., R. Gorodetsky, R. Yarom, and V. Dubowitz. 1980. Element analysis of skeletal muscle in Duchenne muscular dystrophy using $x$-ray fluorescence spectrometry. Muscle \& Nerve. 3: 502-508.

15. Borle, A. B. 1967. Membrane transfer of calcium. Clin. Orthop. Relat. Res. 52: 267-291.

16. Borle, A. B. 1968. Calcium transport in cell culture and the effects of parathyroid hormone. In Parathyroid Hormone and Throcalcitonin (Calcitonin). R. V. Talmage and L. F. Belanger, editors. Excerpta Medica, Amsterdam. I. C. S. No. 159. 258-272.

17. Rasmussen, H., and P. Bordier. 1974. The Physiological and Cellular Basis of Metabolic Bone Disease. The Williams and Wilkins Co., Baltimore. 124-127.

18. Berkow, J. W., B. S. Fine, and L. E. Zimmerman. 1968. Unusual ocular calcification in hyperparathyroidism. Am. J. Opthalmol. 66: 812-824.

19. Arieff, A. I., and S. G. Massry. 1974. Calcium metabolism of brain in acute renal failure: effects of uremia, hemodialysis, and parathyroid hormone. J. Clin. Invest. 53: 387-392.

20. Guisado, R., A. I. Arieff, and S. Massry. 1977. Muscle water and electrolytes in uremia and the effects of hemodialysis. J. Lab. Clin. Med. 89: 322-331.

21. Premachandra, B. N. 1962. Thyroxine secretion rate in hamster and guinea pig. Proceedings of 22nd International Congress of Physiology, Leiden. 469.

22. Nutting, D. F. 1976. Ontogeny of sensitivity to growth hormone in rat diaphragm muscle. Endocrinology. 98: 1273-1283.

23. Dubowitz, V., and M. H. Brooke. 1973. Muscle Biopsy: A Modern Approach. W. B. Saunders Company, Philadelphia. 5-33.

24. Thompson, S. W. 1966. Selected Histochemical and Histopathological Methods. Charles C Thomas, Publisher, Springfield, Ill. 582-585.

25. Bhattacharya, S. K., J. C. Williams, and G. M. A. Palmieri. 1979. Determination of calcium and magnesium in cardiac and skeletal muscle by atomic absorption spectroscopy using stoichiometric nitrous oxide-acetylene flame. Anal. Lett. 12: 1451-1475.

26. Bhattacharya, S. K. 1977. Simultaneous determination of calcium and magnesium in human blood serum by atomic absorption spectrophotometer. Anal. Lett. 10: 817-830.

27. Willis, J. B. 1970. Atomization problems in atomic absorption spectroscopy. II. Determination of degree of atomization in premixed flames. Spectrochim. Acta Part B At. Spectrosc. 25B: 487-512.

28. Kirk, R. E. 1968. Experimental Design: Procedures for the Behavioral Sciences. Brooks/Cole Publishing Company, Belmont, Calif. 91-93.

29. Patten, B. M., J. P. Bilezikian, L. E. Mallette, A. Prince, W. K. Engel, and G. D. Aurbach. 1974. Neuromuscular disease in primary hyperparathyroidism. Ann. Intern. Med. 80: 182-193.

30. Mallette, L. E., B. M. Patten, and W. K. Engel. 1975. Neu- romuscular disease in secondary hyperparathyroidism. Ann. Intern. Med. 82: 474-483.

31. Bertorini, T. E., S. K. Bhattacharya, and G. M. A. Palmieri. 1981. Muscle calcium content in Duchenne muscular dystrophy. Presented at the 33rd Annual Meeting of the American Academy of Neurology, Toronto, Ontario, 30 April 1981; Neurology. 31: 46.

32. Wrogemann, K., and E. G. Nylen. 1978. Mitochondrial calcium overloading in cardiomyopathic hamsters. J. Mol. Cell. Cardiol. 10: 185-195.

33. Bogin, E., S. G. Massry, and I. Harary. 1981. Effect of parathyroid hormone on rat heart cells. J. Clin. Invest. 67: $1215-1227$.

34. Dayton, W. R., D. E. Goll, M. G. Zeece, R. M. Robson, and W. J. Reville. 1976. A $\mathrm{Ca}^{++}$-activated protease possibly involved in myofibrillar protein turnover. Purification from porcine muscle. Biochemistry. 15: 2150-2158.

35. Dayton, W. R., W. J. Reville, D. E. Goll, and M. H. Stromer. 1976. A $\mathrm{Ca}^{++}$-activated protease possibly involved in myofibrillar protein turnover. Partial characterization of the purified enzyme. Biochemistry. 15: 2159-2167.

36. Kar, N. C., and C. M. Pearson. 1976. A calcium-activated neutral protease in normal and dystrophic human muscle. Clin. Chim. Acta. 73: 293-297.

37. Neerunjun, J. S., and V. Dubowitz. 1979. Increased calcium-activated neutral protease activity in muscles of dystrophic hamsters and mice.J. Neurol. Sci. 40: 105-111.

38. Ishiura, S., H. Murofushi, K. Suzuki, and K. Imahori. 1978. Studies of a calcium-activated neutral protease from chicken skeletal muscle. J. Biochem. 84: 225-230.

39. Stracher, A., E. B. McGowan, and S. A. Shafiq. 1978. Muscular dystrophy: inhibition of degeneration in vivo with protease inhibitors. Science (Wash. D. C.). 200: 50-51.

40. Goldberg, A. L., G. N. DeMartino, and P. Libby. 1979. Influence of thyroid hormones and protease-inhibitors on protein degradation in skeletal muscle. In Current Topics in Nerve and Muscle Research. A. J. Aguayo and G. Karpati, editors. Excerpta Medica, Amsterdam. I. C. S. No. 455. 53-60.

41. Knox, F. G., J. Preiss, J. K. Kim, and T. P. Dousa. 1977. Mechanism of resistance to the phosphaturic effect of the parathyroid hormone in the hamster. J. Clin. Invest. 59: 675-683.

42. Biddulph, D. M., P. F. Hirsch, and P. L. Munson. 1970 Thyrocalcitonin and parathyroid hormone in the hamster. Proceedings of the 2nd International Symposium in Calcitonin. William Heinemann Medical Books, Ltd., London. 392-399.

43. Borle, A. B. 1975. Regulation of cellular calcium metabolism and calcium transport by calcitonin. J. Membr. Biol. 21: 125-146.

44. Barakat, H. A., G. L. Dohm, P. Loesche, E. B. Tapscott, and C. Smith. 1976. Lipid content and fatty acid composition of heart and muscle of the B1O 82.62 cardiomyopathic hamster. Lipids. 11: 747-751.

45. Bajusz, E. 1969. Hereditary cardiomyopathy: a new disease model. Am. Heart J. 77: 686-696.

46. Goldspink, D. F., and G. Goldspink. 1977. Age-related changes in protein turnover and ribonucleic acid of the diaphragm muscle of normal and dystrophic hamsters. Biochem. J. 162: 191-194.

47. Molak, V., A. Stracher, and D. Erlij. 1980. Dystrophic mouse muscle have leaky membranes. Exp. Neurol. 70: $452-457$.

48. Berson, S. A., R. S. Yalow, G. D. Aurbach, and J. T. Potts, Jr. 1963. Immunoassay of bovine and human parathyroid hormone. Proc. Natl. Acad. Sci. U. S. A. 49: 613-617. 